\title{
Psychometric properties of the Russian version of the Utrecht Work Engagement Scale (UWES-9)
}

\author{
Andrey V. Lovakova ${ }^{a^{*}}$, Elena R. Agadullina ${ }^{b}$, Wilmar B. Schaufeli ${ }^{c, d}$ \\ ${ }^{a}$ Center for Institutional Studies, National Research University Higher School of Economics, \\ Moscow, Russia \\ ${ }^{\mathrm{b}}$ School of Psychology, National Research University Higher School of Economics, Moscow, Russia \\ ${ }^{c}$ Research Unit Occupational \& Organizational Psychology and Professional Learning, \\ KU Leuven, Leuven, Belgium \\ ${ }^{\mathrm{d}}$ Department of Psychology, Utrecht University, Utrecht, The Netherlands \\ *Corresponding author. E-mail: lovakov@hse.ru
}

This article aims to analyze the psychometric properties of the Russian version of the Utrecht Work Engagement Scale (UWES-9) by using a sample of 1783 employees of a large Russian organization. We conducted a series of Confirmatory Factor Analysis (CFA) tests of the factorial structure and the configural, metric, scalar, factor variance, factor covariance, and factor means invariances of the model across gender and age groups. The validity of the Russian version of the UWES-9 was investigated by studying its relationship with burnout, job satisfaction, life satisfaction, and turnover intention. The CFA showed that both the 1-factor and the 3-factor models of the UWES-9 fit well with the data, but the 3 -factor model demonstrates a significantly better fit. However, the differences are minor; therefore, in practical terms, the models are identical. Thus the Russian version of the UWES- 9 can be used both as a three-scale measurement and as a single scale of work engagement. Results from the multi-group CFA provided evidence of factorial invariance of the 3 -factor model across gender and age groups. Internal consistencies of the vigor, dedication, and absorption subscales are acceptable. The results also suggested the convergent, discriminant, and incremental validity of the UWES-9, as shown by its relationship with burnout, job satisfaction, life satisfaction, and turnover intention. The article also discusses the differences in levels of work engagement within different gender and age groups. Overall, the results show that the Russian version of the UWES-9 demonstrates acceptable psychometric properties comparable with the original version and those in other languages. The Russian version of the UWES-9 can therefore be recommended for use in research and practice.

Keywords: work engagement, UWES, burnout, positive organizational behavior, measurement 


\section{Introduction}

Since the early 2000s, work and organizational psychology has seen the emergence of a new approach called positive organizational behavior, which concentrates on the study of positively-oriented human resources and psychological capabilities that could improve daily working life (Luthans, 2002). Part of this movement emphasizes the importance of studying not only the working conditions affecting employees negatively, creating conditions such as stress and burnout, but also positive ones, one of the results of which is work engagement. Work engagement is defined as "a positive, fulfilling, work-related state, characterized by vigor, dedication, and absorption” (Schaufeli, Salanova, Bakker, \& González-Romá, 2002, p. 74). Vigor refers to a high level of energy and mental resilience while working, the willingness to invest effort in one's work, and persistence even in the face of difficulties. Dedication is characterized by experiencing a sense of significance, enthusiasm, inspiration, pride, and involvement in one's work. Full concentration and being happily engrossed in one's work, in turn, characterize absorption (Schaufeli, Salanova, et al., 2002).

Most research on engagement has been carried out with the job demandsresources model (Bakker \& Demerouti, 2007; Demerouti, Bakker, Nachreiner, \& Schaufeli, 2001). Research over the past 15 years has shown that work engagement is positively correlated with job resources such as social support, positive feedback, the employee's self-efficacy, work autonomy, and a diversity of work tasks, which help workers cope with job demands. Potential consequences of the high level of work engagement include positive job attitudes (job satisfaction, organizational commitment), physical and psychological health, organizational citizenship behavior, and high level of performance (for reviews see Schaufeli \& Taris, 2014).

Schaufeli et al. (2002) developed the Utrecht Work Engagement Scale, which is the most popular work engagement measure. Multi-group confirmatory factor analyses showed that the UWES is a culturally universal scale (Schaufeli, Bakker, \& Salanova, 2006; Seppälä et al., 2009); therefore, it is extensively used in research worldwide. The psychometric properties of the UWES have been confirmed in many languages: Swedish (Hallberg \& Schaufeli, 2006); Finnish (Seppälä et al., 2009); Japanese (Schaufeli, Shimazu, \& Taris, 2009; Shimazu et al., 2008); Italian (Balducci, Fraccaroli, \& Schaufeli, 2010); Norwegian (Nerstad, Richardsen, \& Martinussen, 2010); Spanish (Extremera, Sanchez-Garcia, Duran, \& Rey, 2012); Chinese (Fong \& Ng, 2012); Hebrew (Littman-Ovadia \& Balducci, 2013); Nepali (Panthee, Shimazu, \& Kawakami, 2014); French (Zecca et al., 2015); Portuguese (Vazquez, Magnan, Pacico, Hutz, \& Schaufeli, 2015); Korean (Römer, 2016); and others.

There is also a Russian language version of the UWES translated by Kutuzova (2006). It was used in research involving Russian-speaking participants (Berezovskaya, 2013; Mandrikova \& Gorbunova, 2012; Polunina, 2009; Shestakova, 2012), but a full psychometric analysis of its performance has not yet been conducted. There has been no published study that has focused on the psychometric analysis of the Russian version of the UWES. The purpose of this study is to test the psychometric properties of the Russian language version of the short Utrecht Work Engagement Scale (UWES-9) (Schaufeli \& Bakker, 2004b). It will examine the factorial structure of the Russian language version of the UWES-9, its internal consistency, and cor- 
relations with different measures of job-related well-being. The differences in work engagement according to the main socio-demographic characteristics (gender, age) will also be explored.

\section{Long and short versions of the UWES}

There are two versions of the UWES: the full one, which includes 17 items, and the short one comprising 9 items (three for each component of work engagement). Both versions possess similar psychometric properties (Schaufeli \& Bakker, 2004b). Research using multiple samples from a range of countries showed that the UWES fit well with empirical data and showed good factorial validity as a 3-factor construct (Schaufeli \& Bakker, 2004a; Schaufeli, Martinez, Pinto, Salanova, \& Bakker, 2002; Schaufeli, Salanova, et al., 2002; Schaufeli, Taris, \& van Rhenen, 2008; Seppälä et al., 2009). However, the 1 -factor construct, which reflects a single scale of engagement, also showed an acceptable fit because of high correlations between the latent factors which reflect the UWES subscales (Schaufeli et al., 2006). Although the 3-factor model fit significantly better with the data than the alternative 1-factor model, in effect both the 3-factor scores for vigor, dedication, and absorption, and the total 9-item score, can be used as indicators of work engagement.

\section{UWES and burnout}

There are two views of the relationship between work engagement and burnout. The first argues that work engagement and burnout are the opposite poles of a common continuum (Maslach \& Leiter, 2008), whereas the alternative view claims that work engagement and burnout are distinct psychological states, and hence require separate measurements (Schaufeli et al., 2006; Schaufeli, Salanova, et al., 2002). Both views have empirical evidence backing them up. One meta-analysis supported the distinctiveness and non-redundancy of these two constructs (Crawford, LePine, \& Rich, 2010) while the other questioned their distinctiveness and independence (Cole, Walter, Bedeian, \& O’Boyle, 2012).

The UWES was developed in the framework of the second perspective. Research in this field has found that the dimensions of burnout relate differently to the UWES scales. Several confirmatory factor analytical studies have shown that the personal accomplishment subscale overlaps with the UWES scales more than other subscales, as evidenced by the better fit of the model with two latent factors: the burnout core factor (exhaustion and depersonalization), and the extended engagement factor, including professional efficacy (Extremera et al., 2012; Schaufeli, Salanova, et al., 2002; Schaufeli et al., 2008; Shimazu et al., 2008).

There are several reasons for the overlap between the professional efficacy scale and the UWES scales. First, the professional efficacy scale is formulated in positive terms, while the emotional exhaustion and depersonalization scales are formulated in negative terms. Since all the items of the UWES are also formulated positively, there is a possibility that the positive orientation may be the cause for additional common variance between these scales. Second, the expansion of the construct of work engagement, due to the component associated with accomplishments, is also consistent with the conceptualization of work engagement as proposed by Maslach and Leiter (1997). This difference in the personal accomplishments from 
the remaining two components of burnout (exhaustion and depersonalization) is also confirmed by other research (Lee \& Ashforth, 1996; Leiter, 1993). Thus, work engagement measured by the UWES and burnout measured by Maslach Burnout Inventory $(\mathrm{MBI})$ are separate, independent constructs.

Their antecedents and consequences confirm this conclusion. On the basis of a review of the literature, Bakker et al. (2014, p. 402) conclude that "[w] hereas job demands are the most important antecedents of burnout, job resources are the most important antecedents of work engagement. In addition, whereas burnout has a negative impact on employee well-being and organizational performance, work engagement is a desirable state with positive consequences." Therefore, we may use the relationship between the UWES scales and burnout scales to investigate the validity of the Russian version of the UWES-9.

\section{UWES, well-being, and turnover intentions}

Work engagement is conceptually related to the employee's subjective well-being. Gonzalez-Roma, Schaufeli, Bakker, and Lloret (2006) suggested that burnout and work engagement are both indicators of employee well-being. Salanova, Del Líbano, Llorens, and Schaufeli (2014) further developed this model and proposed four types of work-related well-being (relaxed, enthusiastic, tense, and fatigued). According to their taxonomy, the enthusiastic type or engaged employee is characterized by experiencing the lowest job demands, the highest job and personal resources, and the highest positive outcomes.

This is in line with previous research. Hakanen and Schaufeli (2012) found that work engagement as measured by the UWES had a positive effect on life satisfaction over time. Christian, Garza, and Slaughter (2011) found that work engagement measured by the UWES is moderately correlated with job satisfaction, and has discriminant validity with respect to it. This result was confirmed by subsequent research (Extremera et al., 2012; Littman-Ovadia \& Balducci, 2013). Littman-Ovadia and Balducci (2013) reported that the UWES-9 and its subscales have stronger correlations with intrinsic job satisfaction than with the extrinsic one. Salanova, Del Líbano, Llorens, and Schaufeli (2014) suggest that engaged employees take pleasure in and are challenged by their jobs. Previous findings also showed that engaged employees have lower turnover intentions (Halbesleben, 2010; Saks, 2006; Schaufeli \& Bakker, 2004a). Thus we may expect that if the Russian version of the UWES-9 is equal to original, it should be positively related to job and life satisfaction, and negatively related to turnover intention.

\section{Method}

\section{Participants and procedure}

The sample included 1783 employees: 516 (29\%) men, 1213 (68\%) women, and 54 participants who did not specify their gender) of a major Russian energy company, which engages in the production and sale of heat and electricity in several regions of Russia (response rate $=53 \%$ ). The mean age of the participants was 36.36 years $(S D=9.55)$, although 57 participants did not indicate their age. The mean general length of employment stood at 15.58 years $(S D=9.99)$, while the mean length of 
employment at this organization was 6.90 years $(S D=6.86)$. The majority of the participants (1341) held non-managerial positions; 249 were line managers, 178 were middle-level managers, and 15 were senior executives.

The participants were invited to fill in the anonymous survey they received via corporate e-mail. They received a message that described the purpose and procedure of the survey, and contained a link to the web-questionnaire. Before starting, the respondents were informed of their right to withdraw from the survey at any time, and that their answers would be kept confidential and used only for research purposes.

\section{Scales}

\section{Work Engagement}

Work engagement was measured by the Russian version of the short Utrecht Work Engagement Scale (UWES-9) (Kutuzova, 2006; Schaufeli \& Bakker, 2004b). The measure consists of three subscales: Vigor (VI), Dedication (DE), and Absorption $(\mathrm{AB})$. Each scale consists of three items. Each item needs to be assessed on a 7-point scale $(1=$ Never, $7=$ Always $)$ (the measure can be downloaded from http:// www.wilmarschaufeli.nl/). Cronbach's alphas of the scales range from .75 to .87 .

\section{Burnout}

Burnout was measured by the Russian analogue of the MBI (Maslach \& Jackson, 1986), which was developed by Vodopiyanova and Starchenkova (2009). The measurement includes 22 items integrated into three subscales: emotional exhaustion, depersonalization, and personal accomplishment. Each item should be assessed on a 7 -point scale $(1=$ Never, $7=$ Daily $)$. Cronbach's alphas of the sub-scales range from .80 to .88 .

\section{Job satisfaction}

Job satisfaction was measured by the Brief Index of Affective Job Satisfaction (Thompson \& Phua, 2012). The scale consists of 7 items, 4 of which are used to measure job satisfaction (for example, "I like my job better than the average person"), the remaining three being distractors (for example, "My job is unusual") and thus not included in the analysis. Each item should be assessed using a 7-point scale $(1=$ Strongly disagree, 7 =Strongly Agree $)$. The items were translated into Russian by the first author of this study. The translation was discussed with a bilingual professional who was not aware of the research objectives. When necessary, the translation of the items was corrected. Cronbach's alpha was .91.

\section{Life satisfaction}

Life satisfaction was measured with the use of the Russian version of the Satisfaction with Life Scale (Diener, Emmons, Larsen, \& Griffin, 1985), which was translated and adapted by Osin and Leontiev (2008). The scale consists of 5 items (for example, "In most ways my life is close to my ideal"), each of which needs to be assessed using a 5 -point scale ( $1=$ Strongly disagree, $5=$ Strongly agree $)$. Cronbach's alpha was .89. 


\section{Turnover intention}

Turnover intention was measured by a single item ("I will look for a new job in the near future") (Bozeman \& Perrewe, 2001), which needs to be assessed using a 7 -point scale ( $1=$ Strongly disagree, $7=$ Strongly agree).

\section{Data analysis}

To check the factor structure of the Russian version of the UWES-9, a series of confirmatory factor analyses (CFA) were performed with the lavaan $\mathrm{R}$ package (Rosseel, 2012), using the maximum likelihood parameter estimates with standard errors and chi-square test statistics that are robust to non-normality (MLR). We compared the two alternative models: the 1-factor model, in which all 9 items were assessed as one common scale of work engagement, and the 3 -factor model, in which items were divided into three factors (each including three items) reflecting the three subscales of work engagement. The CFA results were evaluated by using several indicators: $\chi^{2}$, the root mean square error of approximation (RMSEA); the standardized root mean square residual (SRMR); the comparative fit index (CFI); and the Tucker Lewis Index (TLI). Models showing values of greater than .93 for the CFI and TLI, up to .08 for the RMSEA, and up to .06 for the SRMR were judged as showing a good fit (Byrne, 2011; Hu \& Bentler, 1999).

In order to investigate the measurement invariance of the UWES-9, we performed a series of multi-group CFAs, which tested the configural (same structure across groups), metric (same factor loadings across groups), scalar (same factor loadings and item intercepts across groups), factor variance, factor covariance, and factor means invariances of the model across the gender and age groups (Vandenberg \& Lance, 2000). The differences between the nested models were evaluated by using $\Delta \chi^{2}$ (Satorra \& Bentler, 2001) and $\Delta$ CFI. We relied on the $\Delta$ CFI $>$ .01 criterion of significant difference (Cheung \& Rensvold, 2002). For evidence of convergent and discriminant validity, we used the Spearman correlation coefficients between the UWES-9 and other dimensions such as burnout, and job and life satisfaction.

To examine the incremental validity, we conducted a series of hierarchical regression analyses (ordinary least squares method) to determine the additional power of the UWES-9 in predicting job and life satisfaction and turnover intention, controlling for burnout subscales.

\section{Results}

\section{Descriptive analysis of the items of the Russian version of the UWES-9}

Table 1 shows the descriptive statistics for each item of the Russian version of the UWES-9. The average values of the individual items lie within the range of 4.235.36. For all items, there is a small but non-significant negative skew, reflecting the average value of displacement in the direction of high scores. Items 1, 2, and 8 show a small positive kurtosis, and item 5 shows a small negative kurtosis. The distribution of the scores is "approximately normal" because the skewness and kurtosis are not significant. 
Table 1. Descriptive statistics of the items of the Russian version of the UWES-9

\begin{tabular}{lccccc}
\hline \multicolumn{1}{r}{ Item } & $M$ & $S D$ & Median & Skew & Kurtosis \\
\hline 1. VI-1 [1] & 4.63 & 1.13 & 5 & -.47 & 1.05 \\
2. VI-2 [4] & 4.85 & 1.20 & 5 & -.40 & .48 \\
3. DE-1 [5] & 5.05 & 1.18 & 5 & -.31 & .24 \\
4. DE-2 [7] & 4.73 & 1.31 & 5 & -.23 & .04 \\
5. VI-3 [8] & 4.23 & 1.49 & 4 & -.21 & -.34 \\
6. AB-1 [9] & 4.76 & 1.37 & 5 & -.40 & .04 \\
7. DE-3 [10] & 5.16 & 1.35 & 5 & -.49 & .01 \\
8. AB-2 [11] & 5.36 & 1.16 & 5 & -.53 & .58 \\
9. AB-3 [14] & 4.40 & 1.43 & 4 & -.31 & .03 \\
\hline
\end{tabular}

Note $. \mathrm{VI}=$ Vigor. $\mathrm{DE}=$ Dedication $. \mathrm{AB}=$ Absorption. The square brackets indicate the number of the item in the full version of the UWES-17.

\section{Factorial structure of the Russian version of the UWES-9}

Table 2 shows the $\chi^{2}$ statistics and other fit indices obtained by the CFA of the Russian version of the UWES-9. The 1 -factor model with all 9 items loading on the common factor of work engagement did not show a good fit with the data. The value of the CFI and the TLI were below the threshold of .93, and the value of the RMSEA was above .08. The analysis of the modification indices revealed an error covariance between three pairs of items: VI-1 (1) ("At my work, I feel bursting with energy") and VI-2 (2) ("At my job, I feel strong and vigorous"); VI-3 (5) ("When I get up in the morning, I feel like going to work"), and AB-1 (6) ("I feel happy when I am working intensely"); and AB-2 (8) ("I am immersed in my work") and AB-3 (9) ("I get carried away when I'm working") (value varies from .26 to .41). Error covariances between VI- 1 and VI-2 and AB-2 and AB-3 were also noted in the UWES- 9 versions in other languages (Balducci et al., 2010; Littman-Ovadia \& Balducci, 2013; Seppälä et al., 2009; Zecca et al., 2015).

Since the covariances can be meaningfully explained (sequence, similar wording), we followed the practice of previous authors and decided to include them in the model; we modified the 1-factor model by freeing error covariances VI-1/ $\mathrm{VI}-2$ and $\mathrm{AB}-2 / \mathrm{AB}-3$. The error covariance between VI-3 and AB- 1 is not in line with previous literature, and both items belong to different subscales; thus it was not included in the model. The modified 1-factor model showed an acceptable fit with data (see Table 2). All factor loadings differed significantly from zero ( $p<$ .001 ) and exceeded .55. The general 9-item work engagement scale has high internal consistency ( $\alpha=.92$ [95\% CI: .90-.93]). Relatively high correlation coefficients between the UWES-9 subscales ( $r$ varies from .68 to .79) (see Table 3 ) also confirm the similarity in scores on the UWES-9 items. In other words, the UWES-9 can be considered a single work engagement scale.

The 3-factor model, in which the items are grouped into three subscales (Vigor, Dedication, and Absorption), also did not show good fit with the data. The values of the CFI and the TLI were below the threshold of .93, and the value of the RMSEA was above .08 . The analysis of the modification index showed the same error cova- 
riances as in the 1-factor model (values ranging from .29 to .43). Once modified by freeing the same VI-1/VI-2 and AB-2/AB-3 error covariances, the 3-factor model showed an acceptable fit with the data. All factor loadings differed significantly from zero $(p<.001)$ and exceeded .58. The correlations between latent factors exceeded .90. All three subscales (Vigor, Dedication, and Absorption) had good internal consistency ( $\alpha$ varies from .75 to .87). In other words, the UWES-9 can be considered a three-component measure with three separate subscales. Therefore, both the 1 -factor and the 3-factor models fit well with the data. However, the 3 -factor model showed a significantly better fit with the data $\left(\Delta \chi^{2}=10.75, \Delta d f=3\right.$, $p=.013)$.

Table 2. Goodness of fit indicators for measuring models of the UWES-9

\begin{tabular}{|c|c|c|c|c|c|c|c|c|}
\hline Models & $\chi^{2}$ & $p$ & $d f$ & $\begin{array}{l}\text { RMSEA } \\
{[90 \% \mathrm{CI}]}\end{array}$ & CFI & TLI & SRMR & AIC \\
\hline 1-factor model & 630.39 & $<.001$ & 27 & $.11[.11-.12]$ & .90 & .87 & .05 & 44475.79 \\
\hline $\begin{array}{l}\text { 1-factor model } \\
\text { (modified) }\end{array}$ & 323.66 & $<.001$ & 25 & $.08[.08-.09]$ & .95 & .93 & .03 & 44001.99 \\
\hline 3-factor model & 616.75 & $<.001$ & 24 & $.12[.11-.13]$ & .90 & .85 & .05 & 44409.60 \\
\hline $\begin{array}{l}\text { 3-factor model } \\
\text { (modified) }\end{array}$ & 319.73 & $<.001$ & 22 & $.09[.08-.09]$ & .95 & .92 & .03 & 43987.83 \\
\hline
\end{tabular}

Note. $d f$ - degree of freedom; RMSEA - root mean square error of approximation; CFI - comparative fit index; TLI — Tucker Lewis index; SRMR — standardized root mean square residual; AIC Akaike information criterion.

A series of multi-group CFAs across gender and age groups was conducted to provide evidence of the UWES-9 measurement invariance across different groups. The results of the model fit tests and the model comparison are summarized in Table 4. First, a multi-group CFA was conducted across male and female samples. Models of configural invariance (Model 1a), metric invariance (Model 2a), and scalar invariance (Model 3a) showed an acceptable fit and did not statistically differ from their predecessor models $\left(\Delta \chi^{2}\right.$ test not significant, $\left.\Delta \mathrm{CFI}<.01\right)$. These results suggested an invariant 3-factor structure of the UWES-9 in both samples so that it is possible to compare scores across gender groups. Models of factor variance invariance (Model 4a) and factor covariance invariance (Model 5a) also demonstrated an acceptable fit and did not statistically differ from Model 3a. Thus the ranges of scores on the UWES-9 subscales do not vary across gender groups, and the subscales have the same relationship in male and female samples. Finally, the model of factor mean invariance (Model 6a) also demonstrated an acceptable fit, and statistically did not differ from Model 3a. These results suggest that the 3 -factor model of the UWES-9 is invariant across the male and female samples, and thus allows for the comparison of male and female groups on work engagement.

Second, a multi-group CFA was conducted across different age groups. Participants were divided into three age groups: under 30 (career start), 31-50 (in prime of working lives), and over 50 (past the peak of one's career and approaching retirement). Models of configural invariance (Model 1b), metric invariance (Model 2b), 


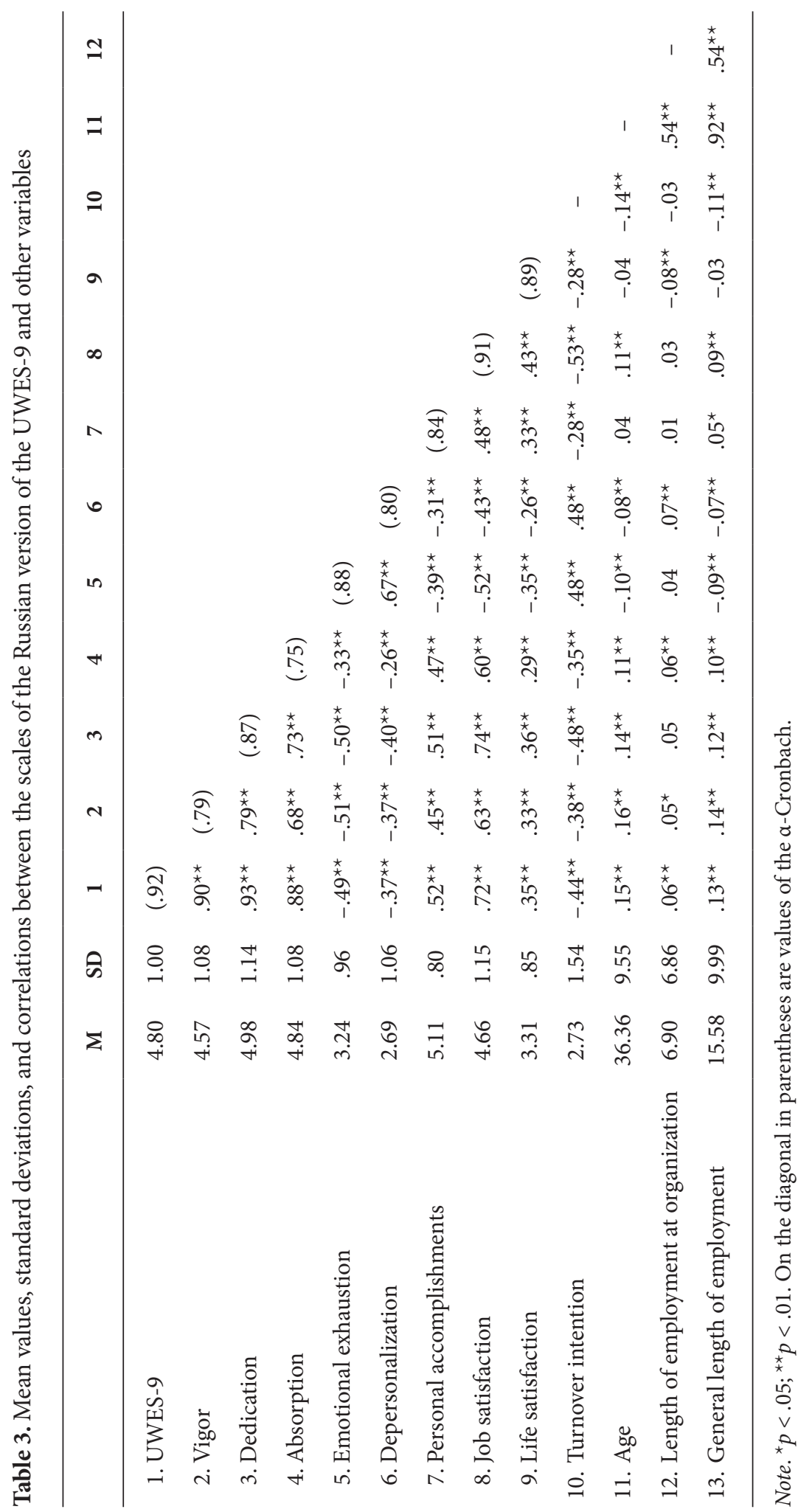




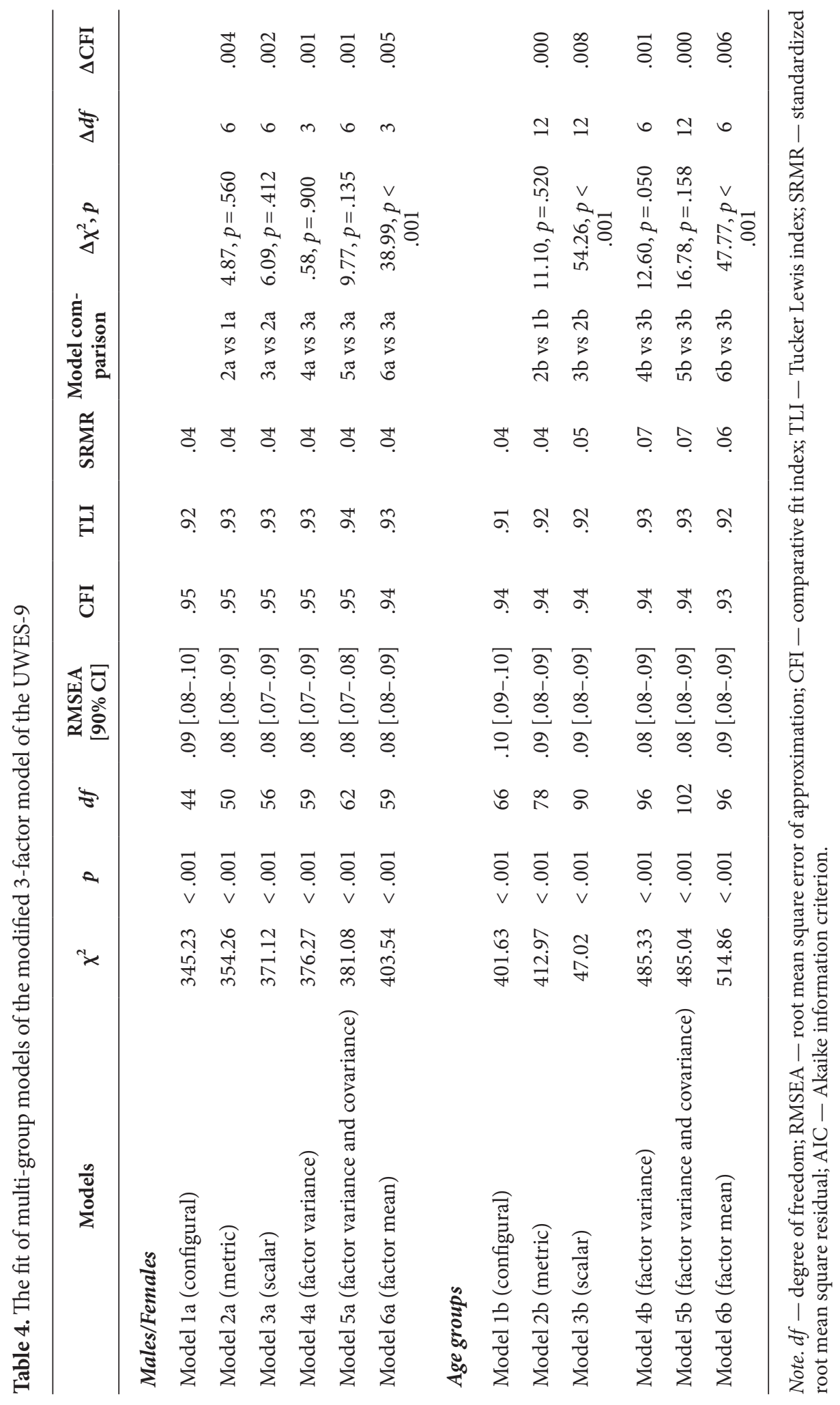


and scalar invariance (Model 3b) had an acceptable fit, but the $\Delta \chi^{2}$ test determined a considerable deterioration in Model $3 \mathrm{~b}$ fit in comparison to Model $2 \mathrm{~b}$. However, a $\Delta$ CFI was below the benchmark of .01; consequently, it was decided not to proceed to examine partial invariance and consider the following models nested within the scalar invariance model (Model $3 \mathrm{~b}$ ). The models of factor variance invariance (Model 4b) and factor covariance invariance (Model 5b) showed an acceptable fit and did not statistically differ from Model $3 \mathrm{~b}$. Thus the range of scores on the UWES-9 subscales does not vary, and has the same relationship across different age groups. The model of factor mean invariance (Model $6 \mathrm{~b}$ ) also demonstrated an acceptable fit and did not significantly differ from Model 3b. This means that the 3-factor model of the UWES-9 is invariant across the age groups and allow for comparison on work engagement.

\section{Convergent, discriminant, and incremental validity of the Russian version of the UWES-9}

Table 3 demonstrates the correlations between the subscales of the UWES-9 and burnout. The UWES-9 subscales correlated slightly more strongly with personal accomplishments ( $r$ ranging from .45 to .51 ), than with the other burnout subscales $(r$ ranges from -.26 to -.51$)$. All subscales and the total UWES-9 score revealed a significant positive correlation with job satisfaction ( $r$ ranges from .60 to .74) and life satisfaction ( $r$ ranges from .29 to .36 ), although the correlations with the former were stronger than with the latter. These results support the convergent and discriminant validity of the Russian version of the UWES-9.

Table 5. Hierarchical multiple regression models

\begin{tabular}{|c|c|c|c|c|c|c|}
\hline & \multicolumn{2}{|c|}{ Job satisfaction } & \multicolumn{2}{|c|}{ Life satisfaction } & \multicolumn{2}{|c|}{ Turnover intention } \\
\hline & Step 1 & Step 2 & Step 1 & Step 2 & Step 1 & Step 2 \\
\hline $\begin{array}{l}\text { Emotional } \\
\text { exhaustion }\end{array}$ & $\begin{array}{l}-.385^{\star * *} \\
(.032)\end{array}$ & $\begin{array}{l}-.174^{\star * *} \\
(.027)\end{array}$ & $\begin{array}{l}-.244^{* * *} \\
(.027)\end{array}$ & $\begin{array}{l}-.198^{\star * *} \\
(.028)\end{array}$ & $\begin{array}{l}.394^{* * *} \\
(.046)\end{array}$ & $\begin{array}{l}.265^{* * *} \\
(.046)\end{array}$ \\
\hline Depersonalization & $\begin{array}{l}-.109^{* * *} \\
(.028)\end{array}$ & $\begin{array}{l}-.081^{* * *} \\
(.023)\end{array}$ & $\begin{array}{l}.000 \\
(.024)\end{array}$ & $\begin{array}{l}.006 \\
(.023)\end{array}$ & $\begin{array}{c}.426^{* * *} \\
(.040)\end{array}$ & $\begin{array}{l}.409^{* * *} \\
(.039)\end{array}$ \\
\hline $\begin{array}{l}\text { Personal } \\
\text { accomplishments }\end{array}$ & $\begin{array}{c}.471^{\star * *} \\
(.030)\end{array}$ & $\begin{array}{l}.133^{\star * *} \\
(.027)\end{array}$ & $\begin{array}{l}.265^{* * *} \\
(.025)\end{array}$ & $\begin{array}{l}.192^{\star * *} \\
(.027)\end{array}$ & $\begin{array}{l}-.146^{* * *} \\
(.042)\end{array}$ & $\begin{array}{l}.060 \\
(.045)\end{array}$ \\
\hline UWES-9 & & $\begin{array}{l}.668^{* * *} \\
(.023)\end{array}$ & & $\begin{array}{l}.145^{\star * *} \\
(.023)\end{array}$ & & $\begin{array}{l}-.407^{\star * *} \\
(.038)\end{array}$ \\
\hline Intercept & $\begin{array}{l}3.799^{* * *} \\
(.197)\end{array}$ & $\begin{array}{c}1.563^{\star * *} \\
(.177)\end{array}$ & $\begin{array}{l}2.743^{* * *} \\
(.164)\end{array}$ & $\begin{array}{l}2.257^{* * *} \\
(.179)\end{array}$ & $\begin{array}{l}1.056^{* * *} \\
(.281)\end{array}$ & $\begin{array}{l}2.421^{\star * *} \\
(.301)\end{array}$ \\
\hline $\mathrm{F}$ & $326.32^{* * *}$ & $587.34^{* * *}$ & $133.88^{\star * *}$ & $112.78^{* * *}$ & $22.80^{\star * *}$ & $204.51^{* * *}$ \\
\hline $\mathrm{R}^{2}$ & .362 & .577 & .189 & .207 & .277 & .322 \\
\hline AIC & 4613 & 3906 & 3985 & 3947 & 5849 & 5741 \\
\hline$\Delta \mathrm{R}^{2}$ & & .215 & & .018 & & .045 \\
\hline $\begin{array}{l}\text { Wald test } \\
\text { (Step } 2 \text { vs Step 1) }\end{array}$ & & $874.61^{\star * *}$ & & $4.314^{\star * *}$ & & $112.72^{\star * \star}$ \\
\hline
\end{tabular}

Note. Standard errors in parentheses. ${ }^{* *} p<.001$. AIC - Akaike information criterion. 
Finally, a series of hierarchical regression analyses were conducted, where job satisfaction, life satisfaction, and turnover intention were dependent variables. The first step included the burnout subscales in the regression equations; the second step added the UWES-9 general score (we did not use the UWES-9 subscales because of multicollinearity problem $-r$ between subscales ranging from .68 to .79). The results of the regression analyses are summarized in Table 5. In all the cases, models including the UWES-9 predicted dependent variables more accurately. Wald tests showed that the models in the second steps are significantly better than in the first steps. Changes in the AICs and $\mathrm{R}^{2}$ from step 1 to step 2 confirm this conclusion. This means that the UWES-9 added a significant amount of variance for predicting job satisfaction (20\%), life satisfaction (2\%), and turnover intention (5\%). This supports the incremental validity of the Russian version of the UWES-9.

\section{Characteristics of the Russian version of the UWES-9 in different demographic and professional groups}

An additional descriptive analysis of the UWES-9 was held in different gender (male/female) and age (under 30,31-50, and over 50) groups. A series of ANOVAs were conducted, in which the UWES-9 and its subscale scores were the dependent variables. The analysis showed that the mean values of the UWES-9 scores and the scores on the vigor and absorption subscales differed significantly between groups of men and women (see Table 6), with women, on average, having higher scores. However, these differences are extremely small (the effect size $\left[\eta_{\mathrm{p}}{ }^{2}\right]$ did not exceed

Table 6. Gender and age differences in UWES-9

\begin{tabular}{|c|c|c|c|c|c|c|}
\hline & $\begin{array}{r}\text { Men } \\
n=51\end{array}$ & & $\begin{array}{l}\text { Women } \\
n=1213 \\
\end{array}$ & \multirow{2}{*}{\multicolumn{2}{|c|}{$F(1,1727)$}} & \multirow[b]{2}{*}{$\eta_{p}^{2}$} \\
\hline & \multicolumn{2}{|c|}{$M(S D)$} & $M(S D)$ & & & \\
\hline UWES-9 & \multicolumn{2}{|c|}{$4.70(1.02)$} & $4.84(1.00)$ & \multicolumn{2}{|c|}{$6.90(p=.009)$} & .004 \\
\hline Vigor & \multicolumn{2}{|c|}{4.47 (1.09) } & $4.62(1.07)$ & \multicolumn{2}{|c|}{$7.32(p=.007)$} & .004 \\
\hline Dedication & $4.95(1$. & & $5.00(1.12)$ & \multicolumn{2}{|c|}{$.58(p=.447)$} & $<.001$ \\
\hline \multirow[t]{3}{*}{ Absorption } & \multicolumn{2}{|c|}{$4.69(1.11)$} & $4.91(1.07)$ & \multicolumn{2}{|c|}{$14.62(p<.001)$} & .008 \\
\hline & $\begin{array}{c}\text { Gr. } 1 \\
\text { Under } 30 \\
n=554\end{array}$ & $\begin{array}{c}\text { Gr. } 2 \\
31-50 \\
n=999\end{array}$ & $\begin{array}{c}\text { Gr. } 3 \\
\text { Greater } 50 \\
n=173\end{array}$ & & & \\
\hline & $M(S D)$ & $M(S D)$ & $M(S D)$ & $F(2,1723)$ & $\eta_{p}^{2}$ & $\begin{array}{c}\text { Post-hoc } \\
\text { comparisons }\end{array}$ \\
\hline UWES-9 & $4.64(1.05)$ & $4.84(.96)$ & $5.13(1.01)$ & $17.83(p<.001)$ & .020 & $1<2<3$ \\
\hline Vigor & $4.36(1.14)$ & $4.65(1.02)$ & $4.87(1.12)$ & $19.36(p<.001)$ & .022 & $1<2<3$ \\
\hline Dedication & $4.82(1.19)$ & $5.01(1.10)$ & $5.37(1.09)$ & $15.88(p<.001)$ & .018 & $1<2<3$ \\
\hline Absorption & $4.72(1.12)$ & $4.86(1.05)$ & $5.17(1.08)$ & $11.33(p<.001)$ & .007 & $1=2<3$ \\
\hline
\end{tabular}

Note. $\eta_{\mathrm{p}}{ }^{2}$ - effect size (Lakens, 2013). Post-hoc comparisons performed by the Tukey HSD test. 
.008). Employees from different age groups also differed on the mean level of work engagement (see Table 6). Employees who are in their early career stages (under 30) displayed the lowest level of the overall UWES-9 and its subscales except on the absorption subscale, whereas employees who are past the peak of their careers and approaching retirement (over 50) had highest level. There is a linear relationship between work engagement and age. However, age had only a minor effect on work engagement (the effect size $\left[\eta_{\mathrm{p}}{ }^{2}\right]$ ranges from .007 to .022). This was also confirmed by the correlations between the overall UWES- 9 and its subscales and age, which are positive and small ( $r$ ranges from .11 to .16 ).

\section{Discussion}

The purpose of this study was to analyze the psychometric properties of the Russian version of the short Utrecht Work Engagement Scale (UWES-9) (Kutuzova, 2006; Schaufeli \& Bakker, 2004b). The Russian version on the UWES-9 has shown good internal consistency reliability; all Cronbach's alphas (both for subscales and for the general scale) exceed the recommended threshold of .70. A series CFA shows that after the addition of two error covariances (VI-1/VI-2, AB-2/AB-3), both the 1-factor and the 3 -factor models fit well with the data. It is possible that these covariances are associated with the order of the items; VI-1/VI-2 and AB-2/AB-3 are sequential and have a similar wording, which creates an additional overlap in their dispersion. These two error covariances were also reported in previous research (Balducci et al., 2010; Littman-Ovadia \& Balducci, 2013; Seppälä et al., 2009; Zecca et al., 2015).

Despite the fact that the 3 -factor model fits better than the 1-factor model, the latent factor correlations exceed .90, which makes them virtually identical. This is a typical finding in other countries as well (Littman-Ovadia \& Balducci, 2013; Mills, Culbertson, \& Fullagar, 2012; Schaufeli et al., 2006; Seppälä et al., 2009). Thus the Russian version of the UWES-9 can also be used both as a 3-scale measure and as a single scale of work engagement. Schaufeli et al. (2006) recommend using the single indicator of the UWES-9 in regression analysis to avoid the problem of multicollinearity caused by the high correlation between the UWES-9 subscales; and also using the values subscales as indicators of the latent factor of work engagement when testing structural equation models. In addition, the three subscales could potentially be used for diagnostic purposes, but only after validation cut-off scores using representative samples. Moreover, our results provide evidence of factorial invariance by gender and age. Thus, the 3 -factor structure is an adequate representation of work engagement, and can be used for comparing male and female and different age groups of employees.

Our study suggests that the Russian version of the UWES-9 has convergent and discriminant validity. In line with previous research (Extremera et al., 2012; Schaufeli, Salanova, et al., 2002; Schaufeli et al., 2008; Shimazu et al., 2008), the UWES-9 subscales correlate more strongly with the personal accomplishments subscale of burnout compared with the other two subscales. The analysis also shows that burnout subscales and the UWES-9 predict different parts of variance in job and life satisfaction and turnover intention. Overall, these results indicate that the Russian version of the UWES-9 corresponds to the theoretical construct of work engagement, and provides evidence for its construct, convergent, and discriminant validity. 
This study has found a link between work engagement and various demographic characteristics of employees. First, the results show that there is a difference in the mean values of two out of three subscales, and the total UWES-9 score, between men and women. Gender differences in work engagement were also reported in some other studies. They showed that women have higher levels of vigor (Fong \& $\mathrm{Ng}, 2012$ ), and men have higher levels of dedication and absorption, as well as a higher total score of work engagement (Schaufeli \& Bakker, 2004b).

However, other studies did not report any difference in the level of work engagement between men and women (Extremera et al., 2012; Zecca et al., 2015). Samples from some countries (Belgium, Germany, Finland, Norway, South Africa, Spain, the Netherlands) reveal this relationship (in different countries men and women differ in different subscales and in different directions), while samples from other countries (Australia, Canada, France) do not (Schaufeli et al., 2006). Altogether, these studies suggest an ambiguous relationship between work engagement and gender, which can be mediated by both the kind of the work, and social or psychological factors. However, the gender differences identified in our research are rather small and have no practical value; therefore, they can be regarded as neither a confirmation nor refutation of previous results.

Second, the results show a weak positive correlation between work engagement and age. This correlation reflects a linear effect of age on engagement, which is confirmed by differences between the three age groups; the older the employee, the higher his/her level of work engagement. A similar weak positive correlation was obtained in several previous studies (Littman-Ovadia \& Balducci, 2013; Panthee et al., 2014; Schaufeli et al., 2006; Schaufeli \& Bakker, 2004b; Zecca et al., 2015). A possible explanation is the "healthy worker effect," meaning that those who are not engaged leave the organization or profession, so that only the engaged workers remain. But as in the previous case, this relationship is relatively weak ( $r$ does not exceed .16) and has no practical value.

Summing up, we can conclude that the Russian version of the UWES-9 shows acceptable psychometric properties in terms of reliability, factor structure, and factorial invariance across gender and age, comparable with the original version, as well as versions in other languages. The scale has high internal consistency and shows good construct validity. Thus, the Russian version of the UWES-9 can be recommended for use in research and practice. However, to use it in practice, a preliminary development of statistical norms is necessary.

There are several limitations in the current study. First, the study was based only on cross-sectional self-reported data, which has implications regarding the data's endogeneity and reliability. This is especially crucial in the case of the measurements of well-being (job and life satisfaction), because the participants' responses partially depend on the situation and their emotional state at the moment of measurement. Therefore, there arises a need for studies with more objective and reliable measurements of well-being. The endogeneity problem can be partially overcome by longitudinal design and repeated measurements. Second, the study involved employees from only one organization. In this case, there is a risk that the specific characteristics of this organization (features of selection, motivation, leadership, etc.) influenced the results, which opens the way for further studies with multiple samples. 


\section{References}

Bakker, A. B., \& Demerouti, E. (2007). The Job Demands-Resources model: state of the art. Journal of Managerial Psychology, 22(3), 309-328. doi: 10.1108/02683940710733115

Bakker, A. B., Demerouti, E., \& Sanz-Vergel, A. I. (2014). Burnout and Work Engagement: The JD-R Approach. Annual Review of Organizational Psychology and Organizational Behavior, 1(1), 389-411. doi: 10.1146/annurev-orgpsych-031413-091235

Balducci, C., Fraccaroli, F., \& Schaufeli, W. B. (2010). Psychometric properties of the Italian version of the Utrecht Work Engagement Scale (UWES-9): A cross-cultural analysis. European Journal of Psychological Assessment, 26(2), 143-149. doi: 10.1027/1015-5759/a000020

Berezovskaya, R. A. (2013). Motivacionnye determinanty uvlechennosti rabotoj u vrachej [Motivational determinants of work engagement among physicians]. Peterburgskij Psihologicheskij Zhurnal [St. Petersburg Psychological Journal], 4, 30-43.

Bozeman, D. P., \& Perrewe, P. L. (2001). The effect of item content overlap on organizational commitment questionnaire-turnover cognitions relationships. Journal of Applied Psychology, 86(1), 161-173. doi: 10.1037//0021-9010.86.1.161

Byrne, B. (2011). Structural equation modeling with Mplus: Basic concepts, applications, and programming. London: Routledge Academic.

Cheung, G. W., \& Rensvold, R. B. (2002). Evaluating Goodness-of-Fit Indexes for Testing Measurement Invariance. Structural Equation Modeling: A Multidisciplinary Journal, 9(2), 233255. http://doi.org/10.1207/S15328007SEM0902_5

Christian, M. S., Garza, A. S., \& Slaughter, J. E. (2011). Work engagement: A quantitative review and test of its relations with task and contextual performance. Personnel Psychology, 64(1), 89-136. doi: 10.1111/j.1744-6570.2010.01203.x

Cole, M. S., Walter, F., Bedeian, A. G., \& O’Boyle, E. H. (2012). Job Burnout and Employee Engagement: A Meta-Analytic Examination of Construct Proliferation. Journal of Management, 38(5), 1550-1581. doi: 10.1177/0149206311415252

Crawford, E. R., LePine, J. A., \& Rich, B. L. (2010). Linking job demands and resources to employee engagement and burnout: A theoretical extension and meta-analytic test. Journal of Applied Psychology, 95(5), 834-848. doi: 10.1037/a0019364

Demerouti, E., Bakker, A. B., Nachreiner, F., \& Schaufeli, W. B. (2001). The job demands-resources model of burnout. Journal of Applied Psychology, 86(3), 499-512. doi: 10.1037//0021-9010 86.3.499

Diener, E., Emmons, R. A., Larsen, R. J., \& Griffin, S. (1985). The Satisfaction With Life Scale. Journal of Personality Assessment, 49(1), 71-75. http://doi.org/10.1207/s15327752jpa4901_13

Extremera, N., Sanchez-Garcia, M., Duran, M. A., \& Rey, L. (2012). Examining the Psychometric Properties of the Utrecht Work Engagement Scale in Two Spanish Multi-occupational Samples. International Journal of Selection and Assessment, 20(1), 105-110. doi: 10.1111/ j.1468-2389.2012.00583.x

Fong, T. C., \& Ng, S. (2012). Measuring Engagement at Work: Validation of the Chinese Version of the Utrecht Work Engagement Scale. International Journal of Behavioral Medicine, 19(3), 391-397. doi: 10.1007/s12529-011-9173-6

Gonzalez-Roma, V., Schaufeli, W. B., Bakker, A. B., \& Lloret, S. (2006). Burnout and work engagement: Independent factors or opposite poles? Journal of Vocational Behavior, 68(1), $165-174$.

Hakanen, J. J., \& Schaufeli, W. B. (2012). Do burnout and work engagement predict depressive symptoms and life satisfaction? A three-wave seven-year prospective study. Journal of Affective Disorders, 141(2-3), 415-424. http://doi.org/10.1016/j.jad.2012.02.043 
Halbesleben, J. R. B. (2010). A meta-analysis of work engagement: Relationships with burnout, demands, resources, and consequences. In A. B. Bakker \& M. P. Leiter (Eds.), Work engagement: A handbook of essential theory and research (pp. 102-117). Hove, East Sussex, England: Psychology Press.

Hallberg, U. E., \& Schaufeli, W. B. (2006). "Same same" but different? Can work engagement be discriminated from job involvement and organizational commitment? European Psychologist, 11(2), 119-127. doi: 10.1027/1016-9040.11.2.119

Hu, L., \& Bentler, P. M. (1999). Cutoff criteria for fit indexes in covariance structure analysis: Conventional criteria versus new alternatives. Structural Equation Modeling: A Multidisciplinary Journal, 6(1), 1-55. doi: 0.1080/10705519909540118

Kutuzova, D. A. (2006). Organizacija dejatelnosti i stil samoreguljacii kak faktory professionalnogo vygoranija pedagoga-psihologa [Organizational activity and style of self-control as factors of professional burnout of the educational psychologist]. (Unpublished $\mathrm{PhD}$ thesis). Lomonosov Moscow State University, Moscow.

Lakens, D. (2013). Calculating and reporting effect sizes to facilitate cumulative science: a practical primer for t-tests and ANOVAs. Frontiers in Psychology, 4, 863. doi: 10.3389/ fpsyg.2013.00863

Lee, R. T., \& Ashforth, B. E. (1996). A meta-analytic examination of the correlates of the three dimensions of job burnout. Journal of Applied Psychology, 81(2), 123-133. doi: 10.1037/00219010.81.2.123

Leiter, M. P. (1993). Burnout as a developmental process: Consideration of models. In W. B. Schaufeli, C. Maslach, \& T. Marek (Eds.), Professional burnout: Recent developments in theory and research (pp. 237-250). Philadelphia, PA, US: Taylor \& Francis.

Littman-Ovadia, H., \& Balducci, C. (2013). Psychometric properties of the Hebrew version of the Utrecht work engagement scale (UWES-9). European Journal of Psychological Assessment, 29(1), 58-63. doi: 10.1027/1015-5759/a000121

Luthans, F. (2002). The need for and meaning of positive organizational behavior. Journal of Organizational Behavior, 23(6), 695-706. doi: 10.1002/job.165

Mandrikova, E., \& Gorbunova, A. (2012). Vzaimosvjaz uvlechennosti rabotoj, lichnostnyh resursov i udovletvorennosti trudom sotrudnikov [Relationship between work engagement, personal resources, and employees' job satisfaction]. Organizacionnâ̂ Psihologiâ (Organizational Psychology), 2(4), 2-22.

Maslach, C., \& Jackson, S. (1986). Maslach burnout inventory manual (2nd ed). Palo Alto, CA: Consulting Psychologists.

Maslach, C., \& Leiter, M. P. (1997). The truth about burnout. San Francisco, CA: Jossey Bass.

Maslach, C., \& Leiter, M. P. (2008). Early predictors of job burnout and engagement. Journal of Applied Psychology, 93(3), 498-512. doi: 10.1037/0021-9010.93.3.498

Mills, M. J., Culbertson, S. S., \& Fullagar, C. J. (2012). Conceptualizing and Measuring Engagement: An Analysis of the Utrecht Work Engagement Scale. Journal of Happiness Studies, 13(3), 519-545. doi: 10.1007/s10902-011-9277-3

Nerstad, C. G. L., Richardsen, A. M., \& Martinussen, M. (2010). Factorial validity of the Utrecht Work Engagement Scale (UWES) across occupational groups in Norway. Scandinavian Journal of Psychology, 51(4), 326-333. doi: 10.1111/j.1467-9450.2009.00770.x

Osin, E. N., \& Leontiev, D. A. (2008). Aprobacija russkojazychnyh versij dvuh shkal jekspressocenki subektivnogo blagopoluchija [Testing of Russian versions of the two scales of a rapid assessment of subjective well-being]. In Materialy III Vserossijskogo sociologicheskogo kongressa. Moscow: Institut sociologii RAN, Rossijskoe obshhestvo sociologov.

Panthee, B., Shimazu, A., \& Kawakami, N. (2014). Validation of Nepalese Version of Utrecht Work Engagement Scale. Journal of Occupational Health, 56(6), 421-429. 
Polunina, O. V. (2009). Sindromy uvlechennosti rabotoj i vygoranija: osobennosti vzaimosvjazej [Work engagement and professional burnout: Correlations' peculiarities]. Psikhologicheskii zhurnal [Psychological Journal], 30(1), 73-85.

Römer, J. (2016). The Korean Utrecht Work Engagement Scale-Student (UWES-S): A factor validation study. TPM - Testing, Psychometrics, Methodology in Applied Psychology, 23, 65-81. doi: 10.4473/TPM23.1.5

Rosseel, Y. (2012). lavaan: An R Package for Structural Equation Modeling. Journal of Statistical Software, 48(2), 1-36. Retrieved from http://www.jstatsoft.org/v48/i02/

Saks, A. M. (2006). Antecedents and consequences of employee engagement. Journal of Managerial Psychology, 21(7), 60-619. doi: 10.1108/02683940610690169

Salanova, M., Del Líbano, M., Llorens, S., \& Schaufeli, W. B. (2014). Engaged, Workaholic, Burned-Out or Just 9-to-5? Toward a Typology of Employee Well-being. Stress and Health, 30(1), 71-81. doi: 10.1002/smi.2499

Satorra, A., \& Bentler, P. M. (2001). A scaled difference chi-square test statistic for moment structure analysis. Psychometrika, 66(4), 507-514. doi: 10.1007/BF02296192

Schaufeli, W. B., \& Bakker, A. B. (2004a). Job demands, job resources, and their relationship with burnout and engagement: A multi-sample study. Journal of Organizational Behavior, 25(3), 293-315. doi: 10.1002/job.248

Schaufeli, W. B., \& Bakker, A. B. (2004b). Test manual for the Utrecht Work Engagement Scale. Unpublished manuscript, Utrecht University, The Netherlands. Utrecht. Retrieved from http:// www.schaufeli.com

Schaufeli, W. B., Bakker, A. B., \& Salanova, M. (2006). The measurement of work engagement with a short questionnaire: A Cross-national study. Educational and Psychological Measurement, 66(4), 701-716. doi: 10.1177/0013164405282471

Schaufeli, W. B., Martinez, I. M., Pinto, A. M., Salanova, M., \& Bakker, A. B. (2002). Burnout and engagement in university students: A cross-national study. Journal of Cross-Cultural Psychology. doi: 10.1177/0022022102033005003

Schaufeli, W. B., Salanova, M., Bakker, A. B., \& González-Romá, V. (2002). The Measurement of Engagement and Burnout: A two sample confirmatory Factor Analytic Approach. Journal of Happiness Studies, 3(1), 71-92. doi: 10.1023/A:1015630930326

Schaufeli, W. B., Shimazu, A., \& Taris, T. W. (2009). Being driven to work excessively hard: The evaluation of a two-factor measure of workaholism in the Netherlands and Japan. CrossCultural Research, 43(4), 320-348. doi: 10.1177/1069397109337239

Schaufeli, W. B., \& Taris, T. W. (2014). A Critical review of the job demands-resources model: Implications for improving work and health. In G. F. Bauer \& O. Hämmig (Eds.), Bridging occupational, organizational and public health (pp. 43-68). Dordrecht: Springer Netherlands. doi: 10.1007/978-94-007-5640-3_4

Schaufeli, W. B., Taris, T. W., \& van Rhenen, W. (2008). Workaholism, burnout, and work engagement: Three of a kind or three different kinds of employee well-being? Applied Psychology: An International Review, 57(2), 173-203. doi: 10.1111/j.1464-0597.2007.00285.x

Seppälä, P., Mauno, S., Feldt, T., Hakanen, J., Kinnunen, U., Tolvanen, A., \& Schaufeli, W. B. (2009). The construct validity of the Utrecht Work Engagement Scale: Multisample and longitudinal evidence. Journal of Happiness Studies, 10(4), 459-481. doi: 10.1007/s10902008-9100-y

Shestakova, K. N. (2012). Factors of professional burnout in actors [Faktory professionalnogo vygoranija akterov]. Psikhologicheskie Issledovaniya [Psychological Studies], 5(25), 7.

Shimazu, A., Schaufeli, W. B., Kosugi, S., Suzuki, A., Nashiwa, H., Kato, A., ... Kitaoka-Higashiguchi, K. (2008). Work engagement in Japan: Validation of the Japanese version of 
the Utrecht Work Engagement Scale. Applied Psychology: An International Review, 57(3), 510-523. doi: 10.1111/j.1464-0597.2008.00333.x

Thompson, E. R., \& Phua, F. T. T. (2012). A Brief Index of Affective Job Satisfaction. Group \& Organization Management, 37(3), 275-307. oi: 10.1177/1059601111434201

Vandenberg, R. J., \& Lance, C. E. (2000). A review and synthesis of the measurement invariance literature: Suggestions, Practices, and recommendations for organizational research. Organizational Research Methods, 3(1), 4-70. doi: 10.1177/109442810031002

Vazquez, A. C. S., Magnan, E. dos S., Pacico, J. C., Hutz, C. S., \& Schaufeli, W. B. (2015). Adaptation and validation of the Brazilian version of the Utrecht Work Engagement Scale. Psico-USF, 20, 207-217. Retrieved from http://www.scielo.br/scielo.php?script=sci_ arttext\&pid=S1413-82712015000200207\&nrm=iso

Vodopiyanova, N., \& Starchenkova, E. (2009). Sindrom vygoranija: diagnostika i profilaktika [Burnout syndrome: diagnosis and prevention]. SPb: Piter.

Zecca, G., Györkös, C., Becker, J., Massoudi, K., de Bruin, G. P., \& Rossier, J. (2015). Validation of the French Utrecht Work Engagement Scale and its relationship with personality traits and impulsivity. Revue Européenne de Psychologie Appliquée/European Review of Applied Psychology, 65(1), 19-28. doi: 10.1016/j.erap.2014.10.003

Original manuscript received May 15, 2016 Revised manuscript accepted November 08, 2016 First published online March 31, 2017 